\title{
How proteolytic inhibitors interact with dentin on glass-fiber post luting over 6 months
}

\section{Chaves, Larissa Pinceli}

2018-03

Chaves , L P , Ciantelli , T L , Araujo, D F G , Giacomini , M C , Tjäderhane , L, Candia Scaffa , P M , Honorio , H M \& Wang , L 2018 , ' How proteolytic inhibitors interact with dentin on glass-fiber post luting over 6 months ' , Journal of the Mechanical Behavior of Biomedical Materials, vol. 79 , pp. 348-353 . https://doi.org/10.1016/j.jmbbm.2018.01.011

http://hdl.handle.net/10138/300962

https://doi.org/10.1016/j.jmbbm.2018.01.011

publishedVersion

Downloaded from Helda, University of Helsinki institutional repository.

This is an electronic reprint of the original article.

This reprint may differ from the original in pagination and typographic detail.

Please cite the original version. 


\title{
How proteolytic inhibitors interact with dentin on glass-fiber post luting over 6 months
}

\author{
Larissa Pinceli Chaves ${ }^{\mathrm{a}, \mathrm{b}}$, Thales Lippi Ciantelli ${ }^{\mathrm{a}}$, Diana F.G. Araújo ${ }^{\mathrm{a}, \mathrm{c}}$, \\ Marina Ciccone Giacomini ${ }^{\mathrm{a}}$, Leo Tjäderhane ${ }^{\mathrm{d}, \mathrm{e}}$, Polliana Mendes Candia Scaffa ${ }^{\mathrm{f}}$, \\ Heitor Marques Honório ${ }^{g}$, Linda Wang ${ }^{\mathrm{a}, *}$ \\ a Department of Operative Dentistry, Endodontics and Dental Materials, Bauru School of Dentistry, University of São Paulo, Bauru, SP, Brazil \\ ${ }^{\mathrm{b}}$ Department of Operative Dentistry, Universidade Paranaense, Cascavel, PR, Brazil \\ ${ }^{\mathrm{c}}$ Department of Operative Dentistry, Federal University of Rio Grande do Norte, Natal, RN, Brazil \\ ${ }^{\mathrm{d}}$ Institute of Dentistry, University of Oulu, and Medical Research Center Oulu, Oulu University Hospital and University of Oulu, Oulu, Finland \\ e Department of Oral and Maxillofacial Diseases, University of Helsinki, and Helsinki University Hospital, Helsinki, Finland \\ ${ }^{\mathrm{f}}$ Department of Biological Science, Bauru School of Dentistry, University of São Paulo, Bauru, SP, Brazil \\ ${ }^{g}$ Department of Pediatric Dentistry, Orthodontics and Collective Health Bauru School of Dentistry, University of São Paulo, Bauru, São Paulo, SP, Brazil
}

\section{A R T I C L E I N F O}

\section{Keywords:}

Bond strength

Chlorhexidine

E-64

EDTA

Root canal

\begin{abstract}
A B S T R A C T
Objectives: Enzyme inhibitors minimize the degradation of unprotected collagen of dentin promoted by matrix metalloproteinases (MMPs) and cysteine cathepsins (CCs). As the evidence of their effect on the root canal is limited, this study aimed to evaluate the role of EDTA, chlorhexidine and E-64 as antiproteolytic agents on the bond strength (BS) of glass-fiber posts in root canals.

Materials and methods: Ninety-six bovine roots were distributed in groups for each time point $(\mathrm{n}=8)$. Adper Scotchbond Multipurpose (MP)/ RelyX ARC system was used to lute the post according to the treatment: negative control (NC)- water, EDTA- 17\% ethylenediaminetetraacetic acid, CHX- $\%$ digluconate chlorhexidine, E64-5- $5 \mu \mathrm{M}$ E-64, E-64-10- $10 \mu \mathrm{M}$ E-64 and positive control (PC)- MP associated with activator/ catalyst. Then, slices were subjected to push-out test $(0.5 \mathrm{~mm} / \mathrm{min})$ after $24 \mathrm{~h} / 6$ mons. Data were analyzed by three-way ANOVA/Tukey tests. Failure modes were analyzed $(40 \times)$.

Results: The factors treatment, time, root canal third and the interaction between treatment and time were statistically significant. At $24 \mathrm{~h}$, no negative interactions were observed among the root dentin, bonding system and post. At 6 mons, CHX improved the BS for middle and apical root thirds.

Conclusions: CHX was able to promote beneficial BS after 6 mons, which was not noted for any other tested enzyme inhibitors.
\end{abstract}

\section{Introduction}

Glass-fiber posts are well-supported restorative resource for procedures that require retention in coronal compromised endodontically treated teeth (Sarkis-Onofre et al., 2014; Figueiredo et al., 2015; Skupien et al., 2016). Together with adhesive agents and cements, they offer mechanical and aesthetic properties close to those of natural teeth (Sarkis-Onofre et al., 2014; Figueiredo et al., 2015; Skupien et al., 2016).

The bonding interface between the cement and dentin is a critical concern in post placement, as bonding agents and cements are essentially hydrophilic and are manipulated under technically demanding conditions and subsequently exposed to the oral environment (Tay and
Pashley, 2003; Chersoni et al., 2005; Schwartz, 2006; Fabre et al., 2007; Pashley et al., 2011; Zicari et al., 2012). Regardless of the category, contemporary adhesives lose their stability over time because they are based primarily on hydrophilic monomers that promote greater interaction with moist substrates, making them more susceptible to environmental challenges (Tay and Pashley, 2003; Chersoni et al., 2005; Schwartz et al., 2006; Fabre et al., 2007; Pashley et al., 2011; Zicari et al., 2012). As these monomers undergo water sorption, they promote their hydrolytic degradation overtime (Pashley et al., 2011; Chersoni et al., 2005; Schwartz et al., 2006; Fabre et al., 2007; Pashley et al., 2011; Zicari et al., 2012). New evidence indicates that the intrinsic characteristics of the dental substrate also affect the success of the restoration, which highlights the importance of considering how

\footnotetext{
* Correspondence to: Department of Operative Dentistry, Endodontics and Dental Materials, Bauru School of Dentistry-FOB-USP, Alameda Octávio Pinheiro Brisolla, 9-75, Brazil.

E-mail address: wang.linda@usp.br (L. Wang).
} 
biological components affect the substrate longevity (Lindblad et al., 2012; Tjäderhane et al., 2013; Wang et al., 2013; Araújo et al., 2014; Tjäderhane, 2015). Therefore, to reach satisfactory longevity, both mechanical properties and biological concerns need to be properly considered during clinical development.

Simultaneously, with the degradation of adhesive components, endogenous dentinal proteolytic enzymes matrix metalloproteinases (MMPs) and cysteine cathepsins (CC) cause degradation of denaturalization of the collagen matrix poorly infiltrated by the resin monomers (Lindblad et al., 2012; Tjäderhane et al., 2013; Wang et al., 2013; Araújo et al., 2014; Tjäderhane, 2015). Both enzymes are physiologically present in sound dentin in the latent stage. However, in injurious situations with mineral loss, MMPs and CC are driven to react, especially when the dentin initially exposed to an acidic environment, such as exposure to cariogenic bacteria (Garcia et al., 2009; Nascimento et al., 2011; Vidal et al., 2014), or by the exposure to and activation of dentinal enzymes by etch-and-rinse and self-etch adhesives (Mazzoni et al., 2006, 2015; Apolonio et al., 2017). Without this natural mineral protection, the enzymes are capable of destroying unprotected and denuded collagen fibrils that were not encapsulated by the adhesive (Hebling et al., 2005). Due to the chemical attraction of these enzymes to the collagen, they modify the structure of the collagen scaffold, which creates a deleterious situation for the hybrid layer (Nascimento et al., 2011; Tjäderhane et al., 2013; Tjäderhane, 2015; Vidal et al., 2014). MMPs and CCs denature it, and in addition to the de-bonding hydrolytic degradation that occurs over time, they seriously compromise the clinical performance of the bonding restorations, thus increasing the prevalence of early clinical failures. This evidence indicates that the use of enzyme inhibitors during the adhesive process could be a simple step with the benefit of inactivating MMPs to increase the longevity of the hybrid layer's integrity (Hebling et al., 2005; Carrilho et al., 2010; Nascimento et al., 2011; Vidal et al., 2014).

Root canal procedures are technically complex, and the use of final irrigation solutions is very important to better cleanse the dentin root wall to establish more appropriate conditions for the bonding process (Victorino et al., 2016; Wagner et al., 2017). Therefore, the use of these cleaning solutions combined with an antiproteolytic creates the potential to eliminate deleterious implications with future bonding materials (Victorino et al., 2016; Wagner et al., 2017).

EDTA is an agent commonly employed in root canal procedures for cleaning and chelation of dentin (Wagner et al., 2017). It is a wellknown MMP inhibitor and thus has been suggested to inhibit MMPs in root canal treatments (Thompson et al., 2012), although the long-term effects of dentinal MMPs has been questioned (Carrilho et al., 2009; Nascimento et al., 2011). To date, CHX has been the most investigated agent used in root canals (Tjäderhane et al., 2013; Wang et al., 2013; Araújo et al., 2014), as it is commonly applied as a disinfectant due to its antimicrobial potential, substantivity (Carrilho et al., 2010), wide availability and low cost. CHX has also been shown to be effective against CCs (Scaffa et al., 2012). E-64 is a CC-specific inhibitor that has been investigated as a treatment for degenerative diseases (Turk and Guncar, 2003). Based on the principle of inhibition of the proteolytic action, this agent was also purposed for the treatment of dentin degradation (Nascimento et al., 2011) and could also be used adjunctively in bonding procedures.

Investigations of the role of CHX and EDTA describe their enzymatic inhibition associated with dentin bonding strategies. Their mechanisms are primarily associated with their capability to interact with MMPs using calcium to inhibit their degradation actions. However, despite several investigations regarding CCs and their degradation potential, no specific investigations have been performed in root canal procedures, where the CC mechanism of action is more associated with the direct interaction with dentin. Therefore, there is a lack of information regarding the possibility of the application of E-64 as a specific CC inhibitor, despite its potential benefits in the dental bonding process. Thus, the comparison among these agents in different concentrations with the most commonly applied enzymatic agents is a worthy clinical investigation.

The aim of this study was to clarify the interaction of different antiproteolytic agents using a dentin bonding system and root dentin and their implication on the bond strength of a fiberglass post. The null hypotheses were that there would be no differences in post bond strength between the inhibitors or between the different locations of the root canal for up to 6 mons.

\section{Materials and methods}

\subsection{Experimental design}

This in vitro study involved the analysis of three factors: the agent of pretreatment of the root canal (in six levels), time (in two levels) and root third (in three levels). The main response variable was the bond strength as measured through a push-out test. Failure mode was also assessed.

\subsection{Specimen preparation}

Ninety-six bovine roots were stored in $0.1 \%$ thymol saline solution at $4{ }^{\circ} \mathrm{C}$, which was renewed weekly. The roots were prepared in accordance with previous investigations (Wang et al., 2013; Araújo et al., 2014). For standardization, teeth with no signs of severe wear, fracture, hypoplasia or decalcification were sectioned at the cementoenamel junction with a low-speed precision saw (Isomet, Buehler, Lake Bluff, IL, USA) with copious water cooling to obtain 17-mm-long roots. Only canals with round shape were selected. An endodontic access cavity was prepared, and working length was established at $16 \mathrm{~mm}$. The root canals were instrumented with K-files (Dentsply Maillefer, Ballaigues, Switzerland) of size 45 . The canals were irrigated with deionized water preceding the use of each instrument. After instrumentation and final irrigation, root canals were dried with absorbent paper points (Tanari, Manacapuru, AM, Brazil) and obturated with gutta-percha points (Tanari, Manacapuru, AM, Brazil) and calcium hydroxide-based sealer (Sealer 26 - Dentsply, Rio de Janeiro, RJ, Brazil) using the lateral compaction technique.

After $7 \mathrm{~d}$ storage at $100 \%$ humidity at $37{ }^{\circ} \mathrm{C}$, gutta-percha was removed with a size 2 Gates drill maintaining at least $3 \mathrm{~mm}$ of obturation in the apical third to create a standard post space of $13 \mathrm{~mm}$ from the CEJ. Post preparation was completed with a low-speed drill provided by the manufacturer of the post-system. The materials used are described in Tables 1, 2. Microscopy assessment was performed in order to avoid the presence of residual sealer on the internal root walls.

The specimens were randomly divided into 6 groups $(n=8)$ for each evaluation time, according to the procedures presented in the Table 3. The root canals were acid-etched with $37 \%$ phosphoric acid (Acid gel - Villevie, Joinville, SC, Brazil) for $15 \mathrm{~s}$, washed with water for $30 \mathrm{~s}$ and dried with paper points, leaving the surface slightly moist as instructed by the manufacturer. Root canals were then irrigated with one of the following agents: $17 \%$ ethylenediaminetetraacetic acid (EDTA), 2\% digluconate chlorhexidine (CHX), $5 \mu \mathrm{M} \mathrm{E-64} \mathrm{(E-64-5),}$ $10 \mu \mathrm{M} \mathrm{E}-64$ (E-64-10), or deionized water (positive and negative control groups, PC and NC respectively) for $30 \mathrm{~s}$ and dried with absorbent paper points. For PC, MP was used adjunctively with activator and catalyst agents as an adhesive: the activator was applied with disposable microbrush for $10 \mathrm{~s}$ and gently dried for $5 \mathrm{~s}$. Next, the primer was also applied for $10 \mathrm{~s}$ and gently dried for $5 \mathrm{~s}$, followed by the application of the catalyst for $5 \mathrm{~s}$. The excess was removed using absorbent paper points. In the other experimental groups, the primer and bonding agent were also applied with a disposable microbrush following manufacturer's instructions. Before cementation, size 2 Exacto posts (Angelus, Londrina, PR, Brazil) were cleaned with 37\% phosphoric acid, silane coupled (Primer Silano, Angelus, Londrina, PR, Brazil) and allowed to dry for $1 \mathrm{~min}$. The dual cure resin cement (Rely X 
Table 1

Materials used for the preparation of tested specimens.

\begin{tabular}{|c|c|c|c|c|}
\hline Material & Manufacturer & Composition $^{\mathrm{a}}$ & Lot & Classification \\
\hline $\begin{array}{l}\text { RelyX ARC } \\
\text { (ARC) }\end{array}$ & $\begin{array}{l}3 \text { M ESPE, St Paul, MN, } \\
\text { USA }\end{array}$ & $\begin{array}{l}\text { Silicon -treated silica, } \\
2.2 \text { etilene dioxidietil dimethacrylate, bisphenol A diglycidyl methacrylate, ether } \\
\text { dimethacrylate functionalized polymer }\end{array}$ & $\begin{array}{l}\text { N553416 } \\
2016-01\end{array}$ & Dual Resin Cement \\
\hline \multirow[t]{5}{*}{$\begin{array}{l}\text { Adper Scotchbond } \\
\text { Multipurpose (MP) }\end{array}$} & $\begin{array}{l}3 \text { M ESPE, St Paul, MN, } \\
\text { USA }\end{array}$ & 2-hydroxyethylmethacrylate (HEMA), polialcenoic acid & $\begin{array}{l}\text { N470622 } \\
2015-08\end{array}$ & Primer \\
\hline & & $\begin{array}{l}\text { Bisglicidilmethacrylate } \\
\text { (Bis -GMA), }\end{array}$ & N465871 & Adhesive \\
\hline & & 2- hydroxyethylmethacrylate (HEMA), amines, peroxide & $2015-12$ & \\
\hline & & Alcoholic solution of a sulfinic acid salt and a photoinitiator component & $\begin{array}{l}\text { N517285 } \\
2016-09\end{array}$ & Activator \\
\hline & & $\begin{array}{l}\text { Bismethacrylate (1- methylethylidene) bis }[4,1 \text { - phenyleneoxy } 2 \text {-hydroxy }-3,1 \text { - } \\
\text { propanediyl)], 2- hydroxyethyl methacrylate, benzoyl peroxide }\end{array}$ & $\begin{array}{l}\text { N517282 } \\
2016-08\end{array}$ & Catalyst \\
\hline
\end{tabular}

${ }^{\text {a }}$ Information supplied by the manufacturers (technical profile).

ARC, 3 M ESPE, St. Paul, MN, USA) was manually applied to the root canal by means of a lentulo spiral instrument according to the manufacturer's instructions (Mani Inc., Tochigi, Japan). The post was inserted into the root canal space and slightly vibrated to avoid air entrapment. The excess cement was removed, and the system was light activated for $40 \mathrm{~s}$ with an LED light-curing device (Led Radii Cal; SDI, Bayswater, Australia; $1200 \mathrm{~mW} / \mathrm{cm}^{2}$ ).

The specimens were stored in $100 \%$ humidity at $37^{\circ} \mathrm{C}$ for $24 \mathrm{~h}$ or 6 mon. After storage, specimens were attached to the arm of a low-speed diamond saw (Isomet, Buehler, Lake Bluff, IL, USA) and sectioned perpendicular to the long axis under water-cooling. Each root was cut into three $1 \mathrm{~mm}$ thick transverse sections from each third, obtaining a total of nine slices per specimen. For the 6-mon tests, specimens were stored in individual vials at $37^{\circ} \mathrm{C}$ in solution that was renewed at every 2 wk interval.

\subsection{Push-out test and failure mode analysis}

A push-out test was performed at $0.5 \mathrm{~mm} / \mathrm{min}$ by pushing the post in apical-coronal direction using an $0.8-1.3 \mathrm{~mm}$ diameter custom stainless steel cylindrical plunger mounted on a universal testing machine (Instron 3342; Instron Corporation, Canton, MA, USA). The force of post-dislocation was registered at the moment of post displacement. The maximum failure load was recorded in Kgf and converted into MPa. A digital caliper (Mitutoyo digital caliper, Mitutoyo America, Aurora, IL, USA) was used to measure the thickness of the slices, and the bonding surface was calculated according to the formula of a conical frustum: $\mathrm{A}=$ ๆ $(\mathrm{R} 2+\mathrm{R} 1)[\mathrm{h} 2+(\mathrm{R} 2-\mathrm{R} 1) 2] 0.5$, where $\mathrm{R} 1=$ base radius, $\mathrm{R} 2=$ top radius, and $\mathrm{h}=$ height of the frustum.

All specimens were observed by stereomicroscopy (x40 magnification) (Stemi 2000-C; Carl Zeiss, Göottingen, Germany) to determine the debonded failure mode and classified as follows: adhesive failure between cement and dentin (A C/D), adhesive failure between cement and post $(A \mathrm{C} / \mathrm{P})$, mixed failures $(\mathrm{M})$, cohesive failure in the dentin $(\mathrm{CD})$, cohesive failure in the cement (CC), and cohesive failure in the post (CP). The percentage of each type of failure within each group was then
Table 3

Experimental groups.

\begin{tabular}{llll}
\hline Group & Dentin treatment & Adhesive & Cement \\
\hline Positive control & Water & $\begin{array}{l}\text { Activator + MP } \\
\text { Primer + Catalyst } \\
\text { MP Primer + Adhesive }\end{array}$ & RelyX ARC \\
Negative control & Water & MP Primer + Adhesive & \\
Chlorhexidine & $\begin{array}{l}2 \% \text { digluconate } \\
\text { chlorhexidine }\end{array}$ & & \\
EDTA & $\begin{array}{l}17 \% \text { EDTA } \\
\text { E-64-5 }\end{array}$ & $5 \mu \mathrm{M} \mathrm{E-64}$ & \\
E-64-10 & $10 \mu \mathrm{M} \mathrm{E-64}$ & & \\
& & & \\
\end{tabular}

calculated.

\subsection{Statistical analysis}

The assumptions of equality of variance and normal distribution of errors were verified using the Kolmogorov-Smirnov and Bartlett tests, respectively. The data was found to be normally distributed, so mean values of bond strength were compared by three-way ANOVA, followed by a multiple comparison test with the Tukey test $(\mathrm{p}<0.05)$ for proteolytic inhibitors, time and radicular third comparisons.

\section{Results}

Fig. 1 presents the mean push-out bond strength values, standard deviations and results from statistical analysis. The factors treatment ( $p$ $=0.026)$, time $(\mathrm{p}=0.013)$ and root canal thirds $(\mathrm{p}<0.001)$ were statistically significant, as well as the interaction between treatment and time ( $\mathrm{p}=0.002)$.

For the treatment analysis, overall performance shows that PC did not differ compared to any of the other treatments tested in terms of time and third. However, for the 6-mons analysis, the group treated with CHX differed from the PC group, with increasing values in middle and apical thirds. The E64-10 group did not differ from any of the other

Table 2

Description of tested inhibitors aspects.

\begin{tabular}{|c|c|c|c|}
\hline Information & EDTA & Chlorhexidine digluconate & E-64 \\
\hline Manufacturer & Biodinâmica, Londrina, PR, Brazil & FGM, Joinville, SC, Brazil & Sigma Aldrich, St. Louis, MO, USA \\
\hline Initial source & Liquid & Liquid & Powder \\
\hline Appearance & Colorless liquid & Clear liquid, colorless to very faint yellow & White powder \\
\hline Molecular Formula & $\mathrm{C} 10 \mathrm{H} 16 \mathrm{~N} 2 \mathrm{O} 8$ & $\mathrm{C} 22 \mathrm{H} 30 \mathrm{Cl} 2 \mathrm{~N} 10-2 \mathrm{C} 5 \mathrm{H} 12 \mathrm{O} 7$ & C15H27N5O5 \\
\hline Molecular Weight & 292.24 & 897.8 & 357.4 \\
\hline Lot/ Expiration date & $1219 / 122015-10$ & $6432132015-02$ & SLBH6132V 2017-05 \\
\hline Soluble in water & Yes & Yes & Yes \\
\hline
\end{tabular}

* Only groups based on E-64 were manipulated in the laboratory. EDTA and CHX were commercially available. 
Push out bond strength

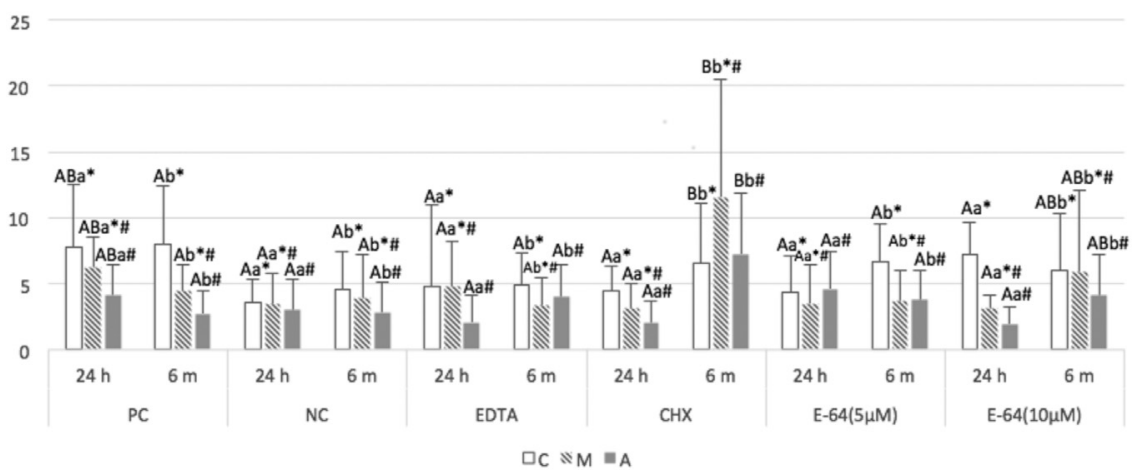

Fig. 1. Percentage of failure mode distribution according to the treatment after $24 \mathrm{~h}$ : A C/P, adhesive failure between the cement and the post; A C/D, adhesive failure between the cement and the dentine; $\mathrm{M}$, mixed failures. groups.

Taking root thirds into account, all the groups showed similar performance, and the cervical third showed statistically greater bond strength values than the apical third in all the evaluated treatments. BS of the middle third did not differ significantly from any of the other thirds.

Table 4 shows the failure analysis at $24 \mathrm{~h}$ and 6 mon. At $24 \mathrm{~h}$, the PC, EDTA and CHX groups exhibited greater adhesive failure between the cement and the dentin. For the NC, E64-5 and E64-10 groups, mixed failures were predominant. For the 6-mons assessments, there was a predominance of mixed failures.

\section{Discussion}

This study indicated that all-purpose enzymatic agents did not immediately jeopardize bond strength when used adjunctively with a dual cure resin system to bond glass-fiber posts into a root canal. However, only chlorhexidine exhibited greater values after 6 mons. Overall, the cervical third of the root demonstrated better performance in terms of BS than the middle and apical thirds. Based on these performances, all of the tested hypotheses were rejected.

The enzymatic potential of different agents against MMPs and CCs has been established, but investigations similar to a clinical scenario are required to assess their actual role and establish technical protocols. As the physiological roles and potential interactions of MMPs and CCs in dentin are not completely understood (Lindblad et al., 2010; Tersariol et al., 2010; Tjäderhane et al., 2013; Giacomini et al., 2017; Umer et al., 2017), this study aimed to evaluate if their use negatively affected the bond ability in root canals initially and after 6 mons. MMPs correspond to proteases implicated in dentin matrix destruction and are known to degrade almost all components of the extracellular matrices, especially highly cross-linked triple-helical collagen (Tjäderhane et al., 2013; Vidal et al., 2014). Regarding CCs, CC-B seems to be related to prior

Table 4

Percentage of failure mode distribution according to the treatment after $24 \mathrm{~h}$ and 6 months, respectively.

\begin{tabular}{|c|c|c|c|c|c|c|}
\hline \multirow[t]{3}{*}{ Groups } & \multicolumn{6}{|c|}{ Failure mode } \\
\hline & \multicolumn{2}{|c|}{ A C/D } & \multicolumn{2}{|c|}{$\mathrm{A} \mathrm{C} / \mathrm{P}$} & \multicolumn{2}{|c|}{ Mixed } \\
\hline & $24 \mathrm{~h}$ & $6 \mathrm{~m}$ & $24 \mathrm{~h}$ & $6 \mathrm{~m}$ & $24 \mathrm{~h}$ & $6 \mathrm{~m}$ \\
\hline Positive control & 72 & 35 & 6 & _- & 22 & 65 \\
\hline Negative control & 32 & 22 & 9 & _- & 59 & 78 \\
\hline Chlorhexidine & 48 & 21 & 14 & 4 & 38 & 75 \\
\hline EDTA & 62 & 19 & 2 & - & 36 & 81 \\
\hline E64-5 & 31 & 21 & 13 & $\overline{1}$ & 56 & 78 \\
\hline E64-10 & 26 & 17 & 2 & 8 & 72 & 75 \\
\hline
\end{tabular}

A C/D, adhesive failure between the cement and the dentin; A C/P, adhesive failure between the cement and the dentin; M, mixed failures. events by degrading non-helical telopeptides of collagen, while CC-K has been shown to be the only CC associated with triple-helical collagenase activity (Vidal et al., 2014).

The significant increase of CC in carious dentin with increasing depth toward the pulp may indicate that MMPs and CCs play a synergetic and dependent role (Tersariol et al., 2010; Nascimento et al., 2011;). Therefore, in situations with significant compromise of the dental structural, their presence and activity might require strategies to recover mechanical properties and resist to oral challenges over time. Additionally, calcium plays an important role for both dental bonding and inhibition action of antiproteolytic agents. Therefore, when these solutions are applied, a competition can occur (Tjäderhane et al., 2013; Tjäderhane, 2015).

This investigation utilized bovine teeth, which is a technique validated by Kato et al., 2011, who demonstrated that the presence and activity of MMP-2 and MMP-9 in bovine roots is similar to that of human roots (Kato et al., 2011). Additionally, the use of deionized water chosen as endodontic irrigating solution does not match the actual clinical scenario, but it is an appropriate way to test the effect of the purposed proteolytic agents and avoids their possible interaction with any other type of interference (Victorino et al., 2016; Wagner et al., 2017).

The first hypothesis was rejected as the inhibitor agents performed in particularly way. CHX is a non-specific enzyme inhibitor that minimizes the activity of a broad spectrum of MMPs and CCs (Scaffa et al., 2012), while EDTA and E-64 act as specific agents against MMPs and CCs, respectively (Thompson et al., 2012; Giacomini et al., 2017). To date, similar studies have been published using CHX (Lindblad et al., 2012; Wang et al., 2013; Araújo et al., 2014; Montagner et al., 2014) but there is a lack of information regarding the effects of a specific cathepsin inhibitor used conjunctively to bonding procedures (Scaffa et al., 2012; Giacomini et al., 2017), especially for post bonding.

As E-64 has been suggested to be a specific CC inhibitor (Nascimento et al., 2011; Scaffa et al., 2012), its use as a proteolytic agent could be of clinical interest. This agent has been previously assessed in research regarding the control of degenerative diseases ( $Q u$ et al., 2015), which lead to analysis of its use in dentin (Nascimento et al., 2011; Scaffa et al., 2012). Scaffa et al., 2012 provided an interesting prospective, suggesting that E-64 capacity would be similar to CHX in bonding procedures. In this study, different concentrations (5 and $10 \mu \mathrm{M} \mathrm{E}-64)$ were compared, levels that were higher than those that had been previously tested for bonding procedures. Additionally, it is important to note that the dentin layer may act as a mechanical barrier, which could reduce its effect when applied.

The null hypothesis that the bond strength is not affected by time was rejected, since differences between the initial and 6-mons assessments were observed in some comparisons. Regarding the initial comparison among the tested groups, the findings of the present study corroborated previous studies that indicated that CHX has no effect on immediate post bond strength when various adhesives, cements and 
posts have been tested in association with etch-and-rinse systems (Lindblad et al., 2010, 2012; Wang et al., 2013; Araújo et al., 2014; Victorino et al., 2016).

The results for the initial time point of this study showed that the E64 at $5 \mu \mathrm{M}$ and $10 \mu \mathrm{M}$ concentrations did not negatively influence post adhesion. It is also noteworthy that the both concentrations of E-64 also produced similar results at 6 mon, suggesting that there is no incompatibility with the adhesive system allowing and indicating its safe use. Similarly, Giacomini et al. (2017) tested E-64 at $5 \mu \mathrm{M}$ and noted perspectives for its use in dentin bonding. Others strategies did not affect initial bond strength but affect it when analyzed overtime (Zenobi et al., 2017).

The group treated with $\mathrm{CHX}$ at 6 mon appeared to be the most effective compared to all other treatments and times. One possible explanation for this finding is the great substantivity of CHX. Over time, its cationic property allows for stable interaction with calcium ions, which likely inactivated the proteolytic enzyme (Carrilho et al., 2010). Wagner et al. (2017) did not observe any significant structural damage when CHX based irrigants were applied. According to Araújo et al. (2014), CHX produced no improvement in bond strength when using the same dual cure cement. This contradictory finding compared to the present study might be related to the use of EDTA in the instrumentation channel as a final irrigant solution. This action may have produced an inactivation of the proteolytic enzymes, which was not employed in the present study. Therefore, the other situations tested by Araújo et al. (2014) might have been interacted by the use of the EDTA solution.

On the other hand, since EDTA is a chelator, it also binds calcium and therefore acts as an MMP inhibitor (Thompson et al., 2012). However, as it exhibits higher solubility in water and chlorhexidine binds more tightly to demineralized dentin, ETDA seems not to be able to maintain the downtime of MMPs for a longer period of time (Thompson et al., 2012). The EDTA group at the 6-mons time point did not show improvement of the bond strength of the root dentin. Unlike early investigations, these results did not increase bond strength with time (Thompson et al., 2012; Toledano et al., 2013; Tekçe et al., 2016;). Thompson et al., 2012 assessed the role of EDTA in demineralized dentin at times of 1, 2 and $5 \mathrm{~min}$ and concluded that its use for 1-2 min would be interesting for resin bonding procedures in the root canal space. However, it is important to note that they assessed the inhibitory capacity trough generic colorimetric MMP assay via absorbance and did not assess its effect on the bonding condition. Further, Tekçe et al., in 2016 tested 0.5 M EDTA for $1 \mathrm{~min}$ and observed positive performance regarding bonding strength for up to 12 mon. However, they employed a universal bonding systems containing MDP, a resin monomer, which also binds to calcium, and so the effect may not be exclusively due to the role of EDTA. In the present study, EDTA was applied for $30 \mathrm{~s}$ in the root dentin and with a bonding system that does not interact with calcium, which may explain the difference in these performances. Compared to CHX, EDTA could cause alterations in the collagen ultrastructure and erosion of peritubular and intertubular dentin, and this action could interfere with adhesion (Wagner et al., 2017).

One relevant point to consider is the $\mathrm{pH}$ of the tested solutions. MMPs and CCs are activated at an acidic $\mathrm{pH}$ between 2.5 and 4.5, and the optimal pH levels in which they act are usually different. CC-B and CC-K have been shown to act in a slightly acidic $\mathrm{pH}$ dentin environment

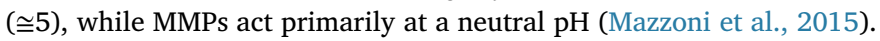
According to $\mathrm{CHX}$ and EDTA manufacturers, the $\mathrm{pH}$ of these solutions is 5.5 and 7.5, respectively, which was also validated by our laboratory tests. E-64-based solutions were prepared at $\mathrm{pH}$ 5.5. Therefore, only commercially available EDTA showed a neutral $\mathrm{pH}$ in accordance with its usual employment in dental applications. Considering these differences in the $\mathrm{pH}$ of the solutions and the optimal $\mathrm{pH}$ for the action of MMPs and CCs, one cannot ignore a possible interaction of these agents with the calcium-based endodontic sealer, even if it was not the main point of this investigation. Additionally, it should be taken into account that $\mathrm{CHX}$ is able to maintain a slightly acidic environment, allowing proteolytic enzymes to be inactivated before the $\mathrm{pH}$ becomes close to neutral. All these scenarios likely contributed to the more effective and notably positive action of CHX compared with the other tested solutions.

Technically, perhaps a longer time of application of the solutions is needed to promote enzyme inactivation, as was observed in previous studies, especially for EDTA (Tjäderhane, 2015; Wagner et al., 2017). In this study, all tested solutions were applied for $30 \mathrm{~s}$ in the root dentin, which was stipulated according to the usual CHX protocol time and seems to be clinically adequate. Following the same rationale, as the E64 solutions were also slightly acidic, future investigations can evaluate increased time of application, but one also has to consider clinical time availability.

The null hypothesis that root thirds do not influence the bond strength was rejected. Regardless of the treatment, the bond strength in apical third systematically presented impaired performance, whereas BS in the middle third decreased overtime. This overall performance reinforces that the root canal represents a restorative challenge, and in this case, mechanical factor drawbacks still appear to be more harmful than the biological features. Toledano et al. (2013) demonstrated that even dentin treated with collagen stabilizer, they are more prone to drawbacks under loading cycle. Therefore, in root canal restorations, likely the challenges may promote more negative impact and all efforts must be addressed.

With the perspective to restrict enzymatic degradation of the adhesive layer, the tested proteolytic inhibitor solutions did not negatively interfere with immediate bond strength of the dual cure luting system to root dentin for up to 6 mons and even improved under the tested conditions. By now, the use of $\mathrm{CHX}$ in adhesive restorations seems to be more reliable. As no negative impact was detected in any circumstance, E64 should be investigated further in different situations as it already has been shown to be a potential inhibitor (Scaffa et al., 2012; Tjäderhane, 2015; Giacomini et al., 2017). Intense investigations based on complementary methodologies have improved knowledge regarding the role of these enzymes on the dentin organic matrix. In a recent publication, Scaffa et al. (2017) highlighted that the main CCs present in dentin, CC-B and CC-K, co-occur on the dentin organic matrix, but they are differently distributed, and both MMPs and CCs are responsible for dentin proteolytic activity. Additionally, evidence indicates that the activity of MMPs is preponderant over CCs in the sound dentin matrix, which may explain the better effectiveness of CHX compared to MMP and E-64. Using aqueous solutions of chlorhexidine as potential proteolytic inhibitors in root canals seems to be a reliable strategy conciliated to dual-cure resin cement in glass-fiber post restorations over 6 mons, which was not noted for the use of EDTA or E64.

In conclusion, evidence indicates the role of MMPs and CCs in collagen degradation, and the use of proteolytic enzyme seems to be a promising adjunctive strategy for bonding procedures with the goal to allow for greater durability of adhesive restorations over time, especially using CHX.

\section{Acknowledgments}

This study was performed by L.P.C. and T.L.C. as fulfillment of their $\mathrm{PhD}$ degree and graduation, respectively (CAPES, Brazil and 2014/ 05717-3 from FAPESP-Fundação de Amparo à Pesquisa do Estado de São Paulo, Brazil). Authors are thankful for 3 M ESPE and Angelus for the donation of the tested materials.

\section{Conflicts of interest}

The authors declare no potential conflicts of interest with respect to the authorship or publication of this article. 


\section{References}

Apolonio, F.M., Mazzoni, A., Angeloni, V., Scaffa, P.M., Santi, S., Saboia, V.P., Tay, F.R., Pashley, D.H., Breschi, L., 2017. Effect of a one-step self-etch adhesive on endogenous dentin matrix metalloproteinases. Eur. J. Oral. Sci. 2, 168-172.

Araújo, D.F.G., Chaves, L.P., Bim Junior, O., Garcia, F.C.P., Ishikiriama, S.K., Honório, H.M., Wang, L., 2014. Influence of $2 \%$ chlorhexidine digluconate on bond strength of a glass-fiber post luted with resin or glass-ionomer based cement. J. Dent. 42, 735-741.

Carrilho, M.R., Tay, F.R., Donnelly, A.M., Agee, K.A., Tjäderhane, L., Mazzoni, A., Breschi, L., Foulger, S., Pashley, D.H., 2009. Host-derived loss of dentin matrix stiffness associated with solubilization of collagen. J. Biomed. Mater. Res. B Appl. Biomater. 90, 373-380.

Carrilho, M.R., Carvalho, R.M., Sousa, E.N., Nicolau, J., Breschi, L., Mazzoni, A., Tjäderhane, L., Tay, F.R., Agee, K., Pashley, D.H., 2010. Substantivity of chlorhexidine to human dentin. Dent. Mater. 26, 779-785.

Chersoni, S., Acquaviva, G.L., Prati, C., Ferrari, M., Grandini, S., Pashley, D.H., Tay, F.R., 2005. In vivo fluid movement through dentin adhesives in endodontically treated teeth. J. Dent. Res. 84, 223-227.

Fabre, H.S.C., Fabre, S., Cefaly, D.F., de Oliveira Carrilho, M.R., Garcia, F.C., Wang, L., 2007. Water sorption and solubility of dentin bonding agentes light-cured with diferente light sources. J. Dent. 35, 253-258.

Figueiredo, F.E.D., Martins-Filho, P.R.S., Faria-e-Silva, A.L., 2015. Do metal post-retained restorations result in more root fractures than fiber post-retained restorations? A systematic review and meta-analysis. J. Endod. 41, 309-316.

Garcia, M.B., Carrilho, M.R., Nör, J.E., Anauate-Netto, C., Anido-Anido, A., Amore, R., Tjärderhane, L., Bretz, W.A., 2009. Chlorhexidine inhibits the proteolytic activity of root and coronal carious dentin in vitro. Caries Res. 43, 92-96.

Giacomini, M.C., Scaffa, P., Chaves, L.P., Vidal, C., Machado, T.N., Honório, H.M., Tjäderhane, L., Wang, L., 2017. Role of proteolytic enzyme inhibitors on carious and eroded dentin associated with a universal bonding system. Oper. Dent. 42, E188-E196.

Hebling, J., Pashley, D.H., Tjäderhane, L., Tay, F.R., 2005. Chlorhexidine arrests subclinical degradation of dentin hybrid layers in vivo. J. Dent. Res. 84, 741-746.

Kato, M.T., Hannas, A.R., Leite, A.L., Bolanho, A., Zarella, B.L., Santos, J., Carrilho, M., Tjäderhane, L., Buzalaf, M.A., 2011. Activity of matrix metalloproteinases in bovine versus human dentine. Caries Res. 45, 429-434.

Lindblad, R.M., Lassila, L.V., Salo, V., Vallittu, P.K., Tjäderhane, L., 2010. Effect of chlorhexidine on initial adhesion of fiber-reinforced post to root canal. J. Dent. 38, 796-801.

Lindblad, R.M., Lassila, L.V.J., Salo, V., Vallittu, P.K., Tjäderhane, L., 2012. One year effect of chlorhexidine on bonding of fibre-reinforced composite root canal post to dentine. J. Dent. 40, 718-722.

Mazzoni, A., Pashley, D.H., Nishitani, Y., Breschi, L., Mannello, F., Tjäderhane, L., Toledano, M., Pashley, E.L., Tay, F.R., 2006. Reactivation of inactivated endogenous proteolytic activities in phosphoric acid-etched dentine by etch-and-rinse adhesives. Biomaterials 27, 4470-4476.

Mazzoni, A., Tjäderhane, L., Checchi, V., Di Lenarda, R., Salo, T., Tay, F.R., Pashley, D.H., Breschi, L., 2015. Role of dentin MMPs in caries progression and bond stability. J. Dent. Res. 94, 241-251.

Montagner, A.F., Sarkis-Onofre, R., Pereira-Cenci, T., Cenci, M.S., 2014. MMP inhibitors on dentin stability: a systematic review and meta-analysis. J. Dent. Res. 93, 733-743.

Nascimento, F.D., Minciotti, C.L., Geraldeli, S., Carrilho, M.R., Pashley, D.H., Tay, F.R., Nader, H.B., Salo, T., Tjäderhane, L., Tersariol, I.L., 2011. Cysteine cathepsins in human carious dentin. J. Dent. Res. 90, 506-511.

Pashley, D.H., Tay, F.R., Breschi, L., Tjäderhane, L., Carvalho, R.M., Carrilho, M., Tezvergil-Mutluay, A., 2011. State of the art of etch-and-rinse adhesives. Dent. Mater. 27, $1-16$.

Qu, Z.G., Ma, X.T., Li, W.H., Zhang, N.Z., Yue, L., Cui, J.M., Cai, J.P., Jia, W.Z., Fu, B.Q.,
2015. Molecular characterization of a cathepsin F-like protease in Trichinella spiralis. Parasit. Vectors 8, 652

Sarkis-Onofre, R., Skupien, J.A., Cenci, M.S., Moraes, R.R., Pereira-Cenci, T., 2014. The role of resin cement on bond strength of glass-fiber posts luted into root canals: a systematic review and meta-analysis of in vitro studies. Oper. Dent. 39, E31-E44.

Scaffa, P.M.C., Vidal, C.M., Barros, N., Gesteira, T.F., Carmona, A.K., Breschi, L., Pashley, D.H., Tjäderhane, L., Tersariol, I.L., Nascimento, F.D., Carrilho, M.R., 2012. Chlorhexidine inhibits the activity of dental cysteine cathepsins. J. Dent. Res. 91, $420-425$.

Scaffa, P.M., Breschi, L., Mazzoni, A., Vidal, C.M., Curci, R., Apolonio, F., Gobbi, P., Pashley, D., Tjäderhane, L., Tersariol, I.L., Nascimento, F.D., Carrilho, M.R., 2017. Co-distribution of cysteine cathepsins and matrix metalloproteases in human dentin. Arch. Oral. Biol. 74, 101-107.

Schwartz, R.S., 2006. Adhesive dentistry and endodontics. Part 2: bonding in the root canal system - the promise and the problems: a review. J. Endod. 32, 1125-1134.

Skupien, J.A., Cenci, M.S., Opdam, N.J., Kreulen, C.M., Huysmans, M.C., Pereira-Cenci, T., 2016. Crown vs. composite for post-retained restorations: a randomized clinical trial. J. Dent. 48, 34-39.

Tay, F.R., Pashley, D.H., 2003. Have dentin adhesives become too hydrophilic? J. Can. Dent. Assoc. 69, 726-731.

Tekçe, N., Tuncer, S., Demirci, M., Balci, S., 2016. Do matrix metalloproteinase inhibitors improve the bond durability of universal dental adhesives? Scanning 2016 (38) 538-544.

Tersariol, I.L., Geraldeli, S., Minciotti, C.L., Nascimento, D., Pääkkönen, V., Martins, M.T., Carrilho, M.R., Pashley, D.H., Tay, F.R., Salo, T., Tjäderhane, L., 2010. Cysteine cathepsins in human dentin-pulp complex. J. Endod. 36, 475-481.

Thompson, J.M., Agee, K., Sidow, S.J., Mcnally, K., Lindsey, K., Borke, J., Elsalanty, M., Tay, F.R., Pashley, D.H., 2012. Inhibition of endogenous dentin matrix metalloproteinases by ethylenediaminetetraacetic acid. J. Endod. 38, 62-65.

Toledano, M., Aguilera, F.S., Yamauti, M., Ruiz-Requena, M.E., Osorio, R., 2013. In vitro load-induced dentin collagen-stabilization against MMPs degradation. J. Mech. Behav. Biomed. Mater. 27, 10-18.

Tjäderhane, L., Nascimento, F.D., Breschi, L., Mazzoni, A., Tersariol, I.L., Geraldeli, S., Tezvrgil-Mutluay, A., Carrilho, M.R., Carvalho, R.M., Tay, F.R., Pashley, D.H., 2013. Optimizing dentin bonding durability: control of collagen degradation by matrix metalloproteinases and cysteine cathespsins. Dent. Mater. 29, 116-135.

Tjäderhane, L., 2015. Dentin bonding: can we make it last? Oper. Dent. 40, 4-18.

Turk, D., Guncar, G., 2003. Lysossomal cysteine proteases (cathepsins): promising drug targets. Acta Crystallogr. D. Biol. Crystallogr. 59, 203-213.

Umer, D., Yiu, C.K., Burrow, M.F., Niu, L.N., Tay, F.R., 2017. Effect of a novel quaternary ammonium silane on dentin protease activities. J. Dent. 58, 19-27.

Victorino, K.R., Kuga, M.C., Duarte, M.A., Cavenago, B.C., Só, M.V., Pereira, J.R., 2016. The effects of chlorhexidine and ethanol on push-out bond strength of fiber posts. Conserv. Dent. 19, 96-100.

Vidal, C.M.P., Tjäderhane, L., Scaffa, P.M., Tersariol, I.L., Pashley, D., Nader, H.B., Nascimento, F.D., Carrilho, M.R., 2014. Abundance of MMPs and cysteine cathepsins in caries affected dentin. J. Dent. Res. 93, 269-274.

Wagner, M.H., da Rosa, R.A., de Figueiredo, J.A., Duarte, M.A., Pereira, J.R., Só, M.V., 2017. Final irrigation protocols may affect intraradicular dentin ultrastructure. Clin. Oral. Investig. 2017 (21), 2173-2182.

Wang, L., Pinto, T.A., Silva, L.M., Araújo, D.F., Martins, L.M., Hannas, A.R., Pedreira, A.P., Francisconi, P.A., Honório, H.M., 2013. Effect of $2 \%$ chlorhexidine digluconate on bond strength of a glass-fibre post to root dentine. Int. Endod. J. 46, 847-854.

Zenobi, W., Feitosa, V.P., Moura, M.E.M., D'arcangelo, C., Rodrigues, L.K.A., Sauro, S.J., 2017. The effect of zoledronate-containing primer on dentin bonding of a universal adhesive. J. Mech. Behav. Biomed. Mater. 77, 199-204.

Zicari, F., De Munck, J., Scotti, R., Naert, I., Van Meerbeek, B., 2012. Factors affecting the cement-post interface. Dent. Mater. 28, 287-297. 